\title{
Artigo
}

\section{Contrastes da Liderança Brasileira em Operações de Paz e Ações Humanitórias: um olhar a partir do Conselho de Defesa Sul-Americano}

Brazilian Leadership Contrasts in Peace Operations and Humanitarian Actions: an outlook from the South American Defense Council

Diana Cristina de Medeiros Viveiros ${ }^{1}$

DOI: 10.5752/P.1809-6182.2018v15.n3.p38

Recebido em: 02 de novembro de 2018 Aprovado em: 09 de fevereiro de 2019

\section{Resumo}

O objetivo desse artigo é compreender a contribuição brasileira no segundo eixo do Conselho de Defesa Sul-Americano (CDS), que trata de cooperação militar, açôes humanitárias e operaçôes de paz. Constatou-se que a participaçâo brasileira nesse eixo contrastou com a sua liderança, experiência e know-how em operaçôes de paz.

Palavras-chave: Brasil; Conselho de Defesa Sul-Americano; Operaçôes de Paz, Açôes Humanitárias.

\begin{abstract}
This article aims to understand Brazilian contribution in the second axis of the South American Defense Council (SADC), which deals with military cooperation, humanitarian actions and peace operations. It was verified that the Brazilian participation in this axis contrasted with its leadership, experience and know-how in peace operations.
\end{abstract}

Key words: Brazil; South American Defense Council; Peace Operations, Humanitarian Actions.

1. Mestre em Estudos Estratégicos da Defesa e da Segurança Internacional, pela Universidade Federal Fluminense (UFF). Graduada em Direito, pela Universidade do Estado do Amazonas (UEA), com habilitação em Direito Internacional, e em Administração, pela Universidade Federal do Amazonas (UFAM). Foz do Iguaçu/Brasil. ORCID 0000-0001-7145-7022 


\section{Introdução}

O Conselho de Defesa Sul-Americano (CDS) foi criado em 2008 com a intençâo de se tornar um foro capaz de construir uma identidade de defesa sul-americana, gerando consensos que pudessem fortalecer a cooperação no continente. A liderança brasileira na criação do CDS foi notável, mas sua continuidade não tem dado sinais de vitalidade.

Desde a sua criação, a atuação do CDS deu-se por intermédio dos chamados planos de ação, cujo primeiro foi definido em 2009, durante a Primeira Reunião de Vice-ministros de Defesa do CDS, em Santiago, no Chile. Esses planos estão divididos em quatro eixos: 1) Política de Defesa; 2) Cooperação Militar, Ações Humanitárias e Operações de Paz; 3) Indústrias e Tecnologia de Defesa; 4) Formação e Capacitação. As ações do CDS relacionadas à cooperação militar estiveram presentes desde o primeiro plano de açáo do Conselho, definido em 2009, cujo segundo eixo de atuação é "cooperação militar, açôes humanitárias e operações de paz". Dessa forma, o presente artigo tem como objetivo compreender a contribuição brasileira em operaçóes de paz e açóes humanitárias via organizaçóes regionais, partindo do estudo do segundo eixo do Conselho de Defesa Sul-Americano. A hipótese traçada é a de que a atuação brasileira nesse eixo do CDS está aquém do seu potencial, especialmente considerando a vasta experiência do Brasil em operaçôes de paz.

A pesquisa realizada segue a forma de abordagem do problema sob a perspectiva qualitativa e, especificamente quanto aos dados disponibilizados nos planos de ação do Conselho de Defesa Sul-Americano, a metodologia utilizada foi a análise de conteúdo. Primeiramente, foi realizado um recorte das açôes do segundo eixo, estabelecendo-se o agrupamento das açóes por temas semelhantes. Os títulos das categorias foram definidos tendo-se como base a própria nomenclatura dos textos dos planos de ação. Em seguida, foram isoladas as açôes por país responsável pela ação, visando realizar um levantamento de quantas açóes o Brasil liderou no segundo eixo do CDS em comparaçáo com os outros países sul-americanos. Vale ressaltar que esse trabalho retrata somente o que está nos planos de ação do Conselho e, portanto, considera-se para fins de análise da atuação brasileira, apenas as inferências e interpretações dos dados analisados.

A primeira seção realiza um panorama geral sobre a contribuição brasileira em operaçôes de paz e açóes humanitárias, considerando a sua liderança diante do comando da Missão das Naçóes Unidas para a Estabilização no Haiti (MINUSTAH), a criação do CCOPAB e o pensamento brasileiro de contribuição por intermédio da defesa. Em seguida, será realizado um panorama geral sobre a liderança brasileira tratando prioritariamente do Conselho de Defesa Sul-Americano, não somente em sua criação, mas principalmente na participação e na consolidação de suas açôes. Por fim, demonstra a atuaçáo brasileira no segundo eixo de atuação do CDS a partir da análise das açóes previstas em seu plano de ação.

\section{Contrastes da liderança brasileira em operações de paz e ações humanitớrias}

O histórico brasileiro e sua participação em operaçōes de paz já foi bem elucidado por diversos autores $^{2}$ e não é objetivo desse artigo adentrar nesse âmbito. Partimos então do momento paradigmático da participação brasileira em operaçôes de paz e de sua influência na cooperação sul-sul: a MINUSTAH, operação iniciada em 2004, com término em 2017.

2. Sugerimos consultar diversos autores que detalham a contribuição brasileira em operaçóes de paz, todos referenciados nesse artigo: FONTOURA, 1999; CAVALCANTE, 2010; NASSER, 2012; KENKEL, 2013a; BLANCO, 2017. 
No âmbito regional, a relevância da participação brasileira na MINUSTAH é inegável e muitos autores reforçam o seu potencial de induzir e aproximar a cooperaçáo entre os países sul-americanos (AGUILAR, 2011; BORRO, 2011; FLEMES, 2010; SOUZA NETO, 2010; SOUZA NETO, 2013, KENKEL, 2013b), tendo inclusive resultado em iniciativas regionais, como a Associação Latino-americana de Centros de Treinamento em Operaçóes de Paz (ALCOPAZ) e o CDS (SOUZA NETO, 2010; BORRO, 2011; SOUZA NETO, 2013).

Além da MINUSTAH, vale ressaltar a contribuiçâao brasileira em diversas operaçôes de paz. No Timor Leste, o país participou de cinco operaçôes de paz; no Congo, o Brasil participou da Missão das Naçôes Unidas na República Democrática do Congo (MONUSCO) e, embora não tenha enviado um contingente militar tão significativo em números, contou com o comando do general brasileiro Carlos Alberto Santos Cruz entre 2013 e 2015 e, do general Elias Rodrigues Martins Filho, nomeado Force Commander em 2018. Além disso, pela primeira vez o Brasil participou do componente marítimo de uma operação de paz das Naçôes Unidas, a Força Interina das Naçóes Unidas no Líbano (UNIFIL) (ANDRADE; HAMANN; SOARES, 2019).

No âmbito interno, outra iniciativa que adveio da MINUSTAH foi a criaçáo do Centro Conjunto de Operaçóes de Paz do Brasil (CCOPAB) ou Centro Sergio Vieira de Mello, conforme versa RAMIRES (2017, p. 25), pois o centro foi "fruto das demandas criadas ao longo da história dessa missão multidimensional de manutenção da paz, bem como do alinhamento do pensamento diplomático nacional e do ministério da Defesa com as novas diretrizes do mais alto escaláo do Secretariado da ONU".

No âmbito regional, reforça-se que a criação da ALCOPAZ, em 2008, reunindo os centros de treinamento de diversos países latino-americanos, permitiu o intercâmbio e treinamento de civis e militares. Em 2008, houve a primeira participação brasileira na Assembleia Anual da ALCOPAZ. Além disso, no início de 2009 houve a incorporação do primeiro oficial estrangeiro ao quadro de instrutores do CIOpPaz ${ }^{3}$, tornando-o internacional e integrado. No mesmo ano, o centro recebeu certificado internacional ${ }^{4}$ de reconhecimento pelo Departamento de Peacekeeping Operations da ONU (DPKO) (RAMIRES, 2017).

O CCOPAB conta ainda com as Equipes Móveis de Treinamento (EMTs), cuja primeira foi enviada a Angola, na cidade de Luanda, em dezembro de 2014, com apoio do Ministério da Defesa e da Marinha do Brasil (CCOPAB, 2014). Além de Angola, o CCOPAB já contribuiu com EMTs Namíbia (2016), Moçambique (2015), Colômbia (2015), e México (2017) (CCOPAB, 2017).

Essa autonomia do CCOPAB pode ser explicada por Alsina Júnior (2017, p. 10) ao tratar que as deficiências administrativas do Ministério da Defesa permitiram com que os três serviços mantivesse um alto grau de autonomia em relação às operaçóes de paz. Para o autor, o CCOPAB foi um avanço em termos de unificação de treinamento, mas não liberou oficiais de defesa civis do fardo representado pela falta de estrutura do ministério.

Ainda trazendo um viés crítico, Blanco (2017), chama de míope e subalterna a inserção brasileira. Para o autor, o fato de o Brasil contribuir essencialmente com tropas reflete uma compreensão limitada da paz, o que justifica o fato de o Ministério da Defesa conduzir e moldar o debate brasileiro nesse assunto.

3. O Centro de Instrução de Operações de Paz (CI Op PAZ) foi criado em 2005, pelo Exército Brasileiro, para e a disseminação dos procedimentos e normas vigentes nas missóes de paz (RAMIRES, 2017, p. 27).

4. Trata do Certificate of Training Recognition, recebido após ter aprimorado os Exercícios Básico e Avançado de Operaçóes de Paz e cumprido as exigências da ONU quanto ao Treinamento Pré-Desdobramento (Pre-Deployment Training) (Ibid, p. 29). 
A cooperação internacional do Brasil via CCOPAB e via CDS são exemplos dessa atuação e, quando partimos para a análise do segundo objeto descritos no segundo eixo do CDS, que trata de Ações Humanitárias, essa contribuição é ainda mais imprecisa nos países da América Latina. Nesse sentido, explica Mônica Hirst (2017, p. 152) que "no plano prático, a lógica que prevalece no campo humanitário é que cada país faz o que pode a partir de sua capacidade de reaçáo e de mobilização de recursos materiais e interinstitucionais".

Para reforçar essa perspectiva unilateral nas açôes humanitárias, exemplifica-se a atuação brasileira ocorrida no terremoto no Chile, em fevereiro de 2012 e nas enchentes na Bolívia, em 2008. No caso do Chile, a "assistência humanitária brasileira foi prestada ao povo chileno, por meio do 'Armazém Humanitário', que, no Brasil, foi na cidade do Rio do Janeiro, em fevereiro de 2009, para atender mais prontamente às demandas recebidas pelo País..." (SILVA, 2011, p. 128). Algumas iniciativas bilaterais e multilaterais também merecem ser destacadas, como é o caso da cooperação da Reuniāo Especializada de Redução de Riscos de Desastres Socioculturais, Defesa Civil, Proteção Civil e Assistência Humanitária (REHU), no âmbito do Mercosul, criada em 2009 com o com o objetivo de estabelecer mecanismos de coordenação e cooperação entre os sistemas nacionais de gestáo de riscos, cuja evoluçâo foi elucidada por Aguilar (2014).

Hirst (2017) reforça o vínculo existente entre a atuação das forças armadas latino-americanas em operações de paz e a capacitação das mesmas para lidar com situaçóes de crise humanitária, o que, de certa forma, revaloriza o papel dos militares. Além disso, a presença das Forças Armadas da América Latina em cenários de crise humanitária responde a orientaçóes e treinamentos recebidos pelo Comando Sul dos Estados Unidos, reflexo de uma tendência mundial, havendo a existência de um viés securitizado nas açôes humanitárias, mesmo quando dissociadas de contextos de conflito e escalada de violência.

Todas essas questōes demonstram um ponto de tangência: a liderança brasileira em operações de paz e ações humanitárias é fortemente influenciada pela ótica de defesa, embora o Brasil também tenha contribuído com policiais, especialistas e tenha participado de debates sobre operaçôes de paz, o que, de certa forma, acaba sendo refletido no âmbito do CDS, organização criada sob a liderança brasileira. Vale ressaltar que a influência dessa cooperação em defesa também aparece no segundo eixo do CDS, cuja ênfase é dada no próprio nome que se inicia com "Cooperação Militar". Assim, antes de adentrar especificamente nas questôes relacionadas ao segundo eixo, serão elucidadas algumas especificidades na liderança brasileira no entorno sul-americano.

\section{A liderança brasileira no entorno sul-americano: caminhos controversos}

A liderança brasileira no âmbito regional é objeto de controvérsia entre os autores e permeia as reflexôes não somente sobre a criação, mas também sobre a continuidade das ações do Conselho de Defesa Sul-Americano. O primeiro desafio ao avaliar a liderança brasileira na região é a falta de consenso dos autores que escrevem sobre o tema, como bem informou Maria Regina Soares de Lima (2013, p. 196), pois alguns autores enfatizam a "pouca disposição do país em assumir os custos de um paymaster", ou são céticos quanto à capacidade de liderança brasileira, ou ainda apontam para uma "liderança branda". Da mesma forma, para Granatto (2015) também não há consenso, pois existiriam setores que defendem "pagar os custos" da integração e os que trabalham em forma contrária. 
O aspecto controverso e dual da política externa brasileira aparece em Malamud, que tece críticas à dualidade da política externa brasileira, classificando-o como um país bifronte, dado a sua contrastante posição na regiáo e no mundo. Por um lado, o país vende-se como igual ou, no máximo, como um facilitador na regiáo, mas não como um líder e muito menos um hegemon. Por outro, luta por qualquer posição de liderança que aparecer. Dessa forma, critica o autor, os governantes apoiam a integração regional no discurso, mas na prática o apoio é mais simbólico. (MALAMUD; RODRIGUEZ, 2013).

Segundo Fucille e Rezende (2013), esse mesmo comportamento dual e eivado de incoerências na política externa brasileira também permeia os autores que tratam da criação do CDS, pois apesar de o Brasil carecer de maturidade para ser um "fiador" das instituiçôes regionais, todas as principais dinâmicas de segurança da regiāo têm passado sob a égide brasileira.

Apesar dessa dicotomia, a liderança brasileira no processo de criação do CDS é elucidada por diversos autores, pois o CDS "só se tornou uma realidade quando o Brasil apoiou a iniciativa e elaborou uma estratégia diplomática ativa que poderia convencer todos os vizinhos da relevância da iniciativa na América do Sul" (VITELLI, 2017, p. 1 - tradução nossa). Ademais, acerca da proposta brasileira e criação do CDS, versam Teixeira Júnior e Silva (2017, p. 2 - tradução nossa) que "Ao propor e liderar a negociação para a criação do CDS, o Brasil demonstrou sua vontade de começar a liderar a regiáo dentro de agendas como a cooperação de defesa”. Da mesma forma, conforme versa Abdul-Hak (2013, p. 143), a crise provocada pelo ataque a Angostura teria servido como "elemento indutor do lançamento da proposta brasileira de conformação do CDS", pois "demonstrou a necessidade de um espaço permanente de concertaçáo sobre defesa que preservasse um canal de diálogo em momentos de aguda tensão e, ao mesmo tempo, estimulasse um processo regular de aproximação política e criação de confiança" (ABDUL-HAK, 2013, p. 143).

O CDS foi criado em um contexto em que governos mais progressistas chegam ao poder na América do Sul, fenômeno cunhado na literatura de "onda rosa", que teve o seu início no final da década de 1990, com a eleição de Hugo Chávez, em 1998. Essa onda de governos progressistas teve impactos nos mecanismos de integração regional, além de ser considerado um fator de aproximação entre esses governos. Buscou-se maior autonomia em relação a organismos internacionais e maior "inserção nas discussóes em torno da regulação global" (SILVA, 2015, p. 16).

Segundo Battaglino (2009), no caso do Brasil, o estímulo ao CDS responde a uma convergência de fatores externos e internos. O autor cita a renovada militarização da agenda dos Estados Unidos, o aumento da tensão na regiâo andina, a "percepção que o Brasil tem de si mesmo, 'potência emergente' e o fato de que "a execução da vontade de liderança do Brasil não teria sido possível sem o sucesso econômico, a estabilidade política, o avanço tecnológico e a rápida recuperação após a crise de 1999” (BATTAGLINO, 2009, p. 80-81).

O fato é que a mesma disposição brasileira para liderar e dar continuidade às açóes do CDS vem sofrendo um significativo declínio, algo que pode ser percebido até mesmo pela análise das açóes disponibilizadas nos planos de ação do Conselho. Vaz, Fuccille e Rezende (2017, p. 17), por exemplo, avaliam a hipótese de que as mudanças no cenário político da América do Sul afetaram diretamente o CDS e suas funções desde 2014, e isso seria resultado tanto da mudança no equilíbrio regional de poder quanto da falta de disposição política interna dos governos locais, especialmente do governo brasileiro, algo que mudou principalmente após o impeachment de Dilma Rousseff. 
A proposta brasileira de criação do CDS "rompeu com a tradição das instituiçôes hemisféricas com a participação dos Estados Unidos nas organizaçóes de defesa coletiva [...] trata-se de uma iniciativa com razoável grau de ineditismo geopolítico" (LIMA, 2013, p. 184). No entanto, partindo dessa característica dual e incoerente da liderança brasileira, não soa controverso o fato de o Brasil lidar de forma táo pouco atuante em uma organização cuja criaçáo foi incentivada por ele mesmo. Em suma, o CDS é uma instituição política, intergovernamental e pouco institucionalizada, o que torna ainda mais difícil a sua sobrevivência ao longo do tempo, fazendo-a dependente da vontade política para existir e continuar a exercer suas funçôes com maestria.

A seção subsequente demonstra um pouco mais da incoerência e da falta de liderança brasileira no CDS, focando especificamente nas questôes que tratam do seu segundo eixo.

\section{A falta de liderança Brasileira no Segundo Eixo do Conselho de Defesa Sul-Americano}

Uma das formas de atuação do CDS ocorre por intermédio dos planos de ação, que é "um documento que constitui uma ferramenta de planejamento e coordenação, o qual permite unidade de critérios e direção estratégica ao CDS, que visa a alcançar os compromissos acordados nas atividades dos 'eixos de trabalho"” (UNASUL, 2008, p. 84). Esses planos são elaborados anualmente, com base nas iniciativas propostas pelos Estados-Membros. O regulamento do CDS traz um título específico para tratar dos planos de ação, o que demonstra a relevância dessa ferramenta de gestão na organização das atividades. Segundo Vaz, Fuccille e Rezende (2017, p. 15), “os planos de ação forneceram, de fato, uma agenda estruturada e um mínimo de orientação para um processo regular de cooperaçáo na defesa...”
Conforme demonstra a Tabela 1, as açóes do Conselho de Defesa, em números, priorizaram o primeiro Eixo. Quanto ao segundo eixo, foco desse trabalho, das 156 açóes do CDS, apenas 35 açôes estiveram no segundo eixo, o que corresponde a $22,43 \%$.

Tabela 1 - Número de ações do CDS por eixo (2009 a 2017)

\begin{tabular}{c|c|c}
\hline Eixo & Total & $\%$ \\
\hline $\begin{array}{c}\text { 1- Política de } \\
\text { defesa }\end{array}$ & 59 & 37,82 \\
\hline $\begin{array}{c}\text { 2- Cooperaçáo } \\
\text { militar, ç̧óes } \\
\text { humanitárias } \\
\text { e operaçóes de } \\
\text { paz }\end{array}$ & 35 & 22,43 \\
\hline $\begin{array}{c}\text { 3- Indústrias e } \\
\text { Tennologia de } \\
\text { Defesa }\end{array}$ & 22 & 14,10 \\
\hline $\begin{array}{c}\text { 4- Formação e } \\
\text { Capacitaçáo }\end{array}$ & 37 & 23,71 \\
\hline Total & 156 & 100 \\
\hline
\end{tabular}

Fonte: Elaborado pela autora a partir dos planos de ação do CDS (2009-2017)

A Tabela 2 demonstra uma visão geral dos planos de ação do CDS, por eixo, no período que compreende os anos de 2009 a 2017, em que "T" representa o total de açóes, e "BR" o total de açóes lideradas pelo Brasil, trazendo também o percentual (\%) das açóes que o Brasil assumiu a responsabilidade por eixo e por ano. Especificamente quanto ao total de açôes planejadas no segundo eixo, no período que vai de 2009 a 2017, a participação brasileira corresponde a $22 \%$ do total de açôes. Das 156 açôes dos planos de ação do CDS, o Brasil ficou responsável por 32 ações, o que corresponde a $20,5 \%$ do total das ações, sendo 8 ações no segundo eixo, o que corresponde a $5,12 \%$ do total das açôes. Na parte da Tabela 2 que trata de ações por ano, verifica-se que foi o ano de 2014 e o ano de 2012 foram os de maior número de ações, sendo 2014 o de maior número de ações lideradas pelo Brasil, com 8 ações no total, cerca de 30\% das contribuições por ano. 
Tabela 2 - Visão Geral Quantitativa dos Planos de Ação do CDS (2009 a 2017)

\begin{tabular}{|c|c|c|c|c|c|c|c|c|c|c|c|c|c|c|c|}
\hline \multicolumn{10}{|c|}{ Quantidade de Ações (Total/Brasil) \% - por eixo } \\
\hline & \multicolumn{1}{|c|}{ Eixo 1 } & \multicolumn{3}{|c|}{ Eixo 2} & \multicolumn{3}{|c|}{ Eixo 3 } & \multicolumn{3}{c|}{ Eixo 4 } & \multicolumn{3}{|c|}{ Açóes por ano } \\
\hline Plano de açáa & T & BR & $\%$ & T & BR & $\%$ & T & BR & $\%$ & T & BR & $\%$ & T & BR & $\%$ \\
\hline $2009 / 2010$ & 6 & 0 & - & 4 & 1 & 25 & 2 & 0 & - & 4 & 1 & 25 & 16 & 2 & 12,5 \\
\hline $2010 / 2011$ & 5 & 0 & - & 6 & 2 & 33 & 7 & 1 & 14 & 3 & 1 & 33 & 21 & 4 & 19,0 \\
\hline 2012 & 13 & 0 & - & 5 & 1 & 20 & 4 & 1 & 25 & 4 & 1 & 25 & 26 & 3 & 11,5 \\
\hline 2013 & 10 & 1 & 10 & 3 & 1 & 33 & 4 & 2 & 50 & 6 & 2 & 33 & 23 & 6 & 26,0 \\
\hline 2014 & 10 & 3 & 30 & 5 & 2 & 40 & 5 & 2 & 40 & 6 & 1 & 16 & 26 & 8 & 30,7 \\
\hline 2015 & 11 & 2 & 18 & 4 & 1 & 25 & 1 & 1 & 100 & 5 & 1 & 20 & 21 & 5 & 23,8 \\
\hline 2016 & 2 & 0 & - & 4 & 0 & - & 1 & 1 & 100 & 4 & 1 & 25 & 11 & 2 & 28,1 \\
\hline 2017 & 2 & 1 & 50 & 4 & 0 & - & 1 & 0 & - & 5 & 1 & 20 & 12 & 2 & 16,6 \\
\hline Total & 59 & 7 & 12 & 35 & 8 & 22 & 25 & 8 & 32 & 37 & 9 & 24 & 156 & 32 & 20,5 \\
\hline
\end{tabular}

Fonte: Elaborado pela autora a partir dos planos de ação do CDS (2009-2017)

Vale ressaltar que, das 156 açóes, a Argentina ficou responsável por 36, o que representa 23,07\% das açóes do CDS, o Brasil veio logo em seguida, com 32, representando $20,5 \%$ do total das ações, seguido do Chile, com 26, que representa 16,6\% do total das açôes. Esses foram os países que, em termos numéricos, mais estiveram à frente das ações, totalizando 94 ações, cerca de 60\%. Para esse cálculo, foi considerado o número de vezes que o país apareceu como responsável principal da ação, seja individual ou em conjunto com outros países.

Para melhor avaliar a experiência brasileira no âmbito do CDS, em seu segundo eixo, foi realizada taxonomia que dividiu as açôes desse eixo em cinco categorias quanto à área de atuação, são elas: 1) Operaçóes de Paz (OP); 2) Desastres Naturais (DN); 3) Desminagem (D); 4) Apoio Humanitário (AH); 5) Medicina Operacional (MO). O Gráfico 1 indica, em percentual, os principais itens do plano de açáo, entre os anos de 2009 e 2017, demonstrando que das 35 ações desse eixo, houve maior número de açóes planejadas quanto às operaçôes de paz, seguidas de atividades relacionadas aos desastres naturais.

Além da taxonomia por área de atuação, as ações do segundo eixo foram classificadas quanto ao tipo de cooperação, os quais foram divididos em quatro categorias pela autora, são elas: 1) Dissemi- nação do Conhecimento - envolve oficinas, simpósios, conferências, fóruns, workshops e seminários (DC); 2) Exercícios Combinados (EC); 3) Grupos de trabalho (GT); 4) Mecanismos de Respostas/ Documentos Conjuntos (MRDC). A Tabela 3 demonstra o percentual das atividades do segundo eixo de acordo com o tipo de cooperaçáo.

\section{Grófico 1- Taxonomia das Ações do segun- do eixo: Área de Atuação}

\section{Medicina operacional $(2,9 \%)$}

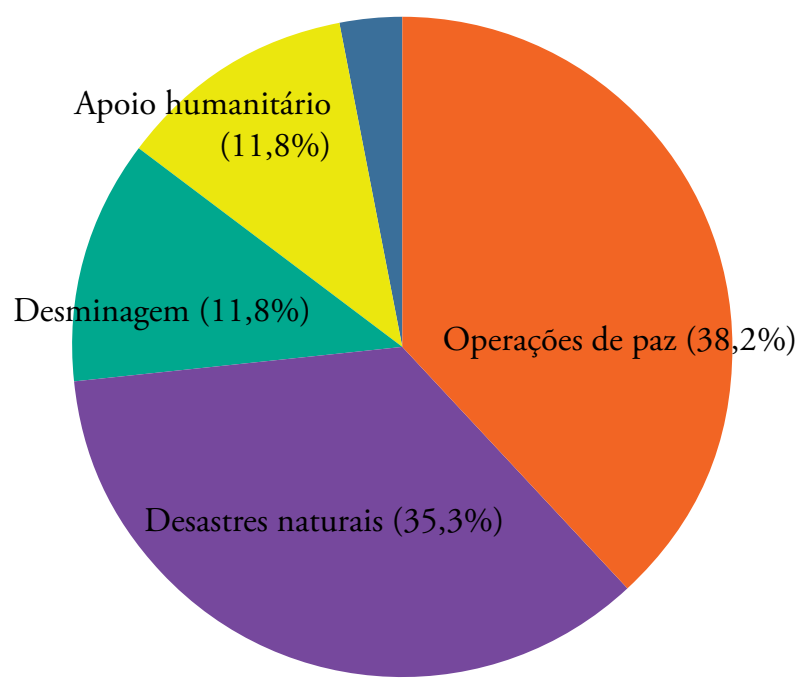

Fonte: Elaborado pela autora a partir dos planos de ação do CDS (2009-2017) 
Tabela 3 - Taxonomia dars Ações do Segundo Eixo: Forma de Cooperação

\begin{tabular}{c|c|c}
\hline Atividades de cooperaçáo & $\mathrm{Qt}$ & $\%$ \\
\hline Disseminaçáo do conhecimento & 14 & 40 \\
\hline Exercícios combinados & 9 & 25,7 \\
\hline $\begin{array}{c}\text { Grupos de trabalho } \\
\begin{array}{c}\text { Documentos/mecanismos de } \\
\text { respostas }\end{array}\end{array}$ & 6 & 17,1 \\
\hline
\end{tabular}

Fonte: Elaborado pela autora a partir dos planos de ação do CDS (2009-2017)

Quanto à forma de cooperação, a taxonomia acima indica uma prevalência por ações que tratam de "Disseminação do Conhecimento". Sobre essas açôes, Vitelli (2017, p. 10) trata da chamada diplomacia do seminário, conceito atribuído a Emanuel Adler ${ }^{5}$, que predominou durante boa parte das açóes do CDS, para a autora esse tipo de atividade é relevante por duas razóes: 1) potencial para criar confiança, aumentar a transparência e oportunidades de diálogo; 2) é uma prática fundamental na especificidade do CDS "que nenhum analista poderia ignorar".

Das ações lideradas pelo Brasil, destacam-se os anos de 2016 e 2017, quando não houve nenhuma ação sob responsabilidade brasileira nesse eixo, conforme Tabela 1. O Quadro I demonstra as ações lideradas pelo Brasil, por ano, de acordo com a taxonomia elaborada pela autora.

A cooperaçấo regional em operaçôes de paz e a liderança brasileira nessas açóes têm induzido a diversas atuaçôes conjuntas, mas não tanto no âmbito do CDS. Em sua grande maioria, essas iniciativas são bilaterais e partem da cooperação entre os próprios centros militares de treinamento em operaçôes de paz. Boa parte das açôes do CDS no segundo eixo ocorreu sem a liderança brasileira. A

5. Segundo Adler diplomacia do seminário são "todos os tipos de diplomacia multilateral (reuniôes de diplomatas, profissionais, funcionários públicos, especialistas acadêmicos e uso de especialistas em missões diplomáticas) visando promover o diálogo político e a cooperaçáo internacional [...] e prevenir ou gerenciar conflitos por meio de conhecimento consensual, técnico ou normativo" (ADLER, 1998, p. 138, tradução nossa).
Argentina, por exemplo, foi responsável por 6 das 13 ações em operaçoóes de paz, tendo realizado os exercícios combinados Unasul I, II, III e IV nos anos de 2011, 2012, 2013 e 2014, respectivamente. O Chile destaca-se na liderança quanto ao Protocolo de emprego das Forças Militares em apoio Humanitário, cujo grupo de trabalho teve início em 2016, com previsão para continuar em 2017.

Nos planos de açấo de 2014 a 2017, a Colômbia ficou responsável pela realização do Fórum Sul-Americano de Experiência em Desminagem Humanitária. O Equador apareceu como responsável por quatro açóes voltadas às Operaçōes de Paz, dentre as quais dois grupos de trabalho e duas atividades de disseminação do conhecimento. O Peru, por sua vez, concentrou açóes relacionadas aos desastres naturais, incluindo a elaboraçáo do atlas de Mapas de Risco de Desastres Naturais na América do Sul. Por fim, o Uruguai ficou responsável por organizar uma conferência sobre liçóes aprendidas em operaçóes de paz.

Conforme dados números disponibilizados na Tabela 2, houve de fato um declínio significativo nas açóes do CDS, coincidindo com o período posterior ao impeachment de Roussef. A diminuição da disposição brasileira em arcar com a motivaçáo de levar as ações do CDS adiante, em termos estruturais, sofreu grande influência do contexto atual da política interna brasileira e do próprio contexto sul-americano, mas esse declínio por si só não é capaz de justificar a lacuna de atenção brasileira quanto ao segundo eixo do CDS, considerando que o padrão e o número açôes propostas anteriormente não refletem a realidade de um país que tem know-how militar em operações de paz.

\section{Considerações Finais}

A partir da análise dos planos de ação do CDS, foi possível perceber que a participação brasi- 
Quadro I - Ações Lideradas pelo Brasil no Segundo Eixo do CDS (2010-2017)

\begin{tabular}{|c|c|c|c|}
\hline Ano & Ação & Atuaçáo & Coop \\
\hline 2010 & Elaborar o inventário das capacidades de defesa que os países oferecem para \\
apoiar as açôes humanitárias & $\begin{array}{c}\text { AH } \\
\text { Consolidar o inventário das capacidades de defesa que os países oferecem para } \\
\text { apoiar as açôes humanitárias }\end{array}$ & MRDC \\
\hline 2011 & $\begin{array}{c}\text { Aperfeiçoar o mecanismo de emprego do inventário das capacidades de defesa dos estados } \\
\text { meombros em caso de desastres naturais }\end{array}$ & DN & MRDC \\
\hline 2013 & $\begin{array}{c}\text { Griar um GT para reunir em um mecanismo de resposta aos desastres naturais: o protocolo de } \\
\text { cooperaçáo apresentado pelo Peru, por meio da atividade 2d e o Inventário de capacidades de } \\
\text { defesa dos Estados para resposta a desastres apresentado pelo Brasil, através da atividade 2c do } \\
\text { Plano de Ação de 2012. Avaliar a possibilidade de usar mecanismos já existentes }\end{array}$ & DN & GT \\
\hline \multirow{2}{*}{2014} & $\begin{array}{c}\text { Manter atividade 2c de 2013: estabelecer mecanismo de resposta a desastres naturais, com } \\
\text { acesso via internet, utilizando o protocolo de cooperaçáo, e disponibilizar o inventário de ca- } \\
\text { pacidade de defesa dos Estados membros do CDS }\end{array}$ & DN & MRDC \\
\cline { 2 - 5 } & $\begin{array}{c}\text { Açáo 2d: organizar uma oficina sobre “operaçóes de manutençáo de paz e açóes humanitárias: } \\
\text { liçóes aprendidas e perspectivas", no Rio de Janeiro }\end{array}$ & OP/AH & DC \\
\hline 2015 & $\begin{array}{c}\text { Desenvolver capacidade na área de treinamento de medicina operativa por intermédio de um } \\
\text { seminário internacional }\end{array}$ & MO & DC \\
\hline
\end{tabular}

Fonte: Elaborado pela autora a partir do modelo taxonômico proposto (2018)

leira, em termos numéricos, especialmente a partir de 2016, esteve aquém de seu potencial de liderança na área de operaçóes de paz e açóes humanitárias. Considerando-se a sua experiência significativa em 14 anos de comando da MINUSTAH, no Haiti, a participação em outras operaçôes de paz e a existência de um CCOPAB que já vem trabalhando para exportar o seu know-how para outros países, conforme panorama da atuação brasileira sintetizado neste artigo, esperava-se uma postura mais ativa nesse eixo.

Questôes políticas e o contexto brasileiro e sul-americano têm contribuído para uma diminuição significativa da cooperação dos países sul-americanos no âmbito da defesa, afetando sobremaneira as perspectivas de integração regional. Além disso, essa cooperação continua sendo realizada prioritariamente por vias bilaterais, conforme demonstrado pela atuaçáo do CCOPAB e outros exemplos relacionados às ações humanitárias.

Esse artigo demonstrou os contrastes da liderança brasileira no âmbito do Conselho de Defesa Sul-Americano, especificamente tratando de operaçốes de paz e açôes humanitárias. Partiu de uma visão crítica nos dois aspectos, demonstrando tanto a in- coerência brasileira na liderança regional, conforme já elucidado por diversos autores, como a liderança brasileira em termos de segurança internacional, ambas com reflexo para o CDS.

Quanto à participação brasileira no segundo eixo do CDS, demonstrou-se uma clara falta de liderança, extremamente contrastante com o papel assumido pelo Brasil na MINUSTAH. Dessa forma, cabe-nos o seguinte questionamento: Por que o Brasil, país sul-americano líder de uma operação de paz que contou com a participaçâo de comandantes brasileiros, com um Centro Conjunto de Operações de Paz extremamente atuante e considerado referência em treinamentos de operações de paz, com o exemplo e know-how aprendidos durante os 14 anos de experiência na MINUSTAH, permaneceu durante os dez anos iniciais do CDS com tâo poucas açôes voltadas a esse eixo de atuação?

\section{Referências}

ABDUL-HAK, A. P. N. T. O Conselho de Defesa Sul-Americano (CDS): Objetivos e interesses do Brasil. Brasília: FUNAG, 2013.

ADLER, E. Seeds of peaceful change: the OSCE's security community-building model (Chapter 4). In: ADLER, E.; 
BARNETT, M (Eds). Security Communities. Cambridge: University Press, 1988, p. 119-160.

AGUILAR, S. L. C. A participação Sul-Americana nas Operaçōes de Paz da ONU: Algumas consideraçôes. Security and Defense Studies Review, [s.l.], v. 12, n. 1, p. 99-116, 2011. Disponível em: <https://repositorio.unesp.br/handle/11449/115404>. Acesso em: 20 abr. 2019.

AGUILAR, S. L. C. A. O mecanismo cooperativo no Mercosul para lidar com desastres. Revista Eletrônica de Direito Internacional, Belo horizonte, v. 14, 2014. Disponível em: <http:// centrodireitointernacional.com.br/publicacoes/revista-eletronica/>. Acesso em: 20 abr. 2019.

ALSINA JUNIOR, J. P. S. Grand Strategy and Peace Operations: the Brazilian Case. Rev. bras. polít. int., Brasília, v.60, n.2, 2017. Disponível em: <http://www.scielo.br/scielo.php?script=sci_arttext\&pid=S0034-73292017000200205>. Acesso em: 20 abr. 2019.

ANDRADE, I. O.; HAMANN, E. P.; SOARES, M. A. A participaçáo brasileira nas operaçóes de paz das Naçóes Unidas: evolução, desafios e oportunidades. Texto para discussão 2442. Instituto de Pesquisa Econômica Aplicada (IPEA). Brasília: IPEA, 2019.

BATTAGLINO, J. O Brasil e a criação do Conselho de Defesa Sul-Americano Uma convergência de vantagens. Nueva Sociedad - Especial em Português, Buenos Aires, 2009. Disponível em: <http://nuso.org/articulo/o-brasil-e-a-criacao-do-conselho-de-defesa-sul-americano-uma-convergencia-de-vantagens/>. Acesso em: 20 abr. 2019.

BLANCO, R. The Brazilian Engagement with Peace Operations: a Critical Analysis. Rev. bras. polít. int., Brasília, v.60, n.2, 2017. Disponível em: <http://www.scielo.br/scielo.php?script=sci_arttext $\&$ pid $=$ S0034-73292017000200206>. Acesso em: 20 abr. 2019.

BORRO, A. L. Regionalización de las misiones de paz: La presencia de latinoamerica em MINUSTAH. In: LIVINGSTONE, A.; ST-PIERRE, K. (Eds). Latin America and Peace Operations: Partners and Perspectives. The Pearson Papers, Ottawa, v. 13, 2011.

CAVALCANTE, F. Rendering peacekeeping instrumental? The Brazilian approach to United Nations peacekeeping during the Lula da Silva years (2003-2010). Rev. bras. polít. int., Brasília, v.53, n.2, p.142-159, 2010. Disponível em: <http://www.scielo.br/scielo.php?script=sci_arttext\&pi$\mathrm{d}=$ S0034-73292010000200008 >. Acesso em: 20 abr. 2019.

CCOPAB. CCOPAB envia sua primeira Equipe Móvel de Treinamento (EMT) a Angola. CCOPAB, Rio de Janeiro, 2014. Disponível em: <http://www.ccopab.eb.mil.br/pt/noticias-do-centro/2014>. Acesso em: 30 out. 2018.

CCOPAB. CCOPAB capacita militares mexicanos para atuarem em Missóes de Paz. CCOPAB, Rio de Janeiro, 2017. Disponível em: <http://www.ccopab.eb.mil.br/pt/noticias-do-centro/145-2017>. Acesso em: 30 out. 2018.
CONSELHO DE DEFESA SUL-AMERICANO (CDS). Plano de Açáo 2009-2010. Santiago: CDS, 2009. Disponível em: $<$ http://ceed.unasursg.org/Espanol/09-Downloads/Esp-PA/PA-CDS-2009-10.pdf>. Acesso em: 25 out. 2018.

CONSELHO DE DEFESA SUL-AMERICANO (CDS). Plano de Açáo 2010-2011. CDS, 2010. Disponível em: $<$ http://ceed.unasursg.org/Espanol/09-Downloads/Esp-PA/PA-CDS-2010-11.pdf>. Acesso em: 03 fev. 2019.

CONSELHO DE DEFESA SUL-AMERICANO (CDS). Plano de Açáo 2012. CDS, 2012. Disponível em: <http://ceed. unasursg.org/Espanol/09-Downloads/Esp-PA/PA-CDS-2012. pdf>. Acesso em: 03 fev. 2019.

CONSELHO DE DEFESA SUL-AMERICANO (CDS). Plano de Açáo 2013. CDS, 2013. Disponível em: <http://ceed. unasursg.org/Espanol/09-Downloads/Esp-PA/PA-CDS-2013. pdf>. Acesso em: 03 fev. 2019.

CONSELHO DE DEFESA SUL-AMERICANO (CDS). Plano de Açáo 2014. CDS, 2014. Disponível em: <http://ceed. unasursg.org/Espanol/09-Downloads/Esp-PA/PA-CDS-2014. pdf>. Acesso em: 03 fev. 2019.

CONSELHO DE DEFESA SUL-AMERICANO (CDS). Plano de Açáo 2015. CDS, 2015. Disponível em: <http://ceed. unasursg.org/Espanol/09-Downloads/Esp-PA/PA-CDS-2015. pdf>. Acesso em 03: fev. 2019.

CONSELHO DE DEFESA SUL-AMERICANO (CDS). Plano de Açáo 2016. CDS, 2016. Disponível em: <http://ceed. unasursg.org/Espanol/09-Downloads/Esp-PA/PA-CDS-2016. pdf>. Acesso em: 03 fev. 2019.

CONSELHO DE DEFESA SUL-AMERICANO (CDS). Plano de Açáo 2017. CDS, 2017. Disponível em: <http://ceed. unasursg.org/Espanol/09-Downloads/Esp-PA/PA-CDS-2017. pdf>. Acesso em: 03 fev. 2019.

FLEMES, D. Brazil: Strategic Option in the Changing World Order (Chapter 4). In: (Ed). Regional Leadership in the Global System - Ideas, Interests and Strategies of Regional Powers, 1st edition. Nova York: Routledge, 2010, p. 93-112.

FONTOURA, P. R. C. T. O Brasil e as Operaçóes de Manutenção da Paz das Nações Unidas. Brasília: FUNAG, 1999.

FUCCILLE, A.; REZENDE, L. P. Complexo regional de segurança da América do Sul: uma nova perspectiva. Contexto int., Rio de Janeiro, v. 35, n. 1, p. 77-104, 2013. Disponível em: <http://www.scielo.br/scielo.php?pi$\mathrm{d}=$ S0102-85292013000100003\&script=sci_abstract\&tln$\mathrm{g}=\mathrm{pt}>$. Acesso em: 20 mar. 2019.

GRANATO, L. Brasil, Argentina e os rumos da integraçáo: o Mercosul e a Unasul. Curitiba: Appris, 2015.

HIRST, M. Conceitos e práticas da ação humanitarian latino-americana no contexto da securitizaçáo global. Estudios internacionales, Santiago, p. 143-178, 2017. Disponível em: <https:// scielo.conicyt.cl/pdf/rei/v49nspe/0719-3769-rei-49-00143. pdf>. Acesso em: 20 abr. 2019. 
KENKEL, K. M. Out of South America to the globe: Brazil's growing stake in peace operations (Chapter 4). In:

(Ed). South America and Peace Operations - Coming of Age. Nova York: Routledge, 2013a, p. 85-110.

KENKEL, K. M. Conclusions: Securing South America's Peace Operations acquis-post MINUSTAH. In: (Ed). South America and Peace Operations - Coming of Age. Nova York: Routledge, 2013b, p. 188-202.

LIMA, M. R. S. Relaçốes Interamericanas: A Nova Agenda Sul-Americana e o Brasil. Lua Nova, São Paulo: CEDEC, n. 90, pp. 167-201, 2013. Disponível em: <http://www.scielo.br/pdf/ ln/n90/a07n90.pdf>. Acesso em: 20 abr. 2019.

MALAMUD, A.; RODRIGUEZ, J. C. Com um pé na região e outro no mundo: O dualismo crescente da política externa brasileira. EI Estudos Internacionais, v. 1, n. 2 jul-dez, p.167-183, 2013. Disponível em: <http://periodicos.pucminas.br/index.php /estudosinternacionais/article/view/6312>. Acesso em: 20 abr. 2019.

NASSER, F. Pax brasiliensis: projeção de poder e solidariedade na estratégia diplomática de participação brasileira em operaçóes de paz da organização das naçóes unidas. In: KENKEL, K. M.; MORAES, R. F. de (Org.). O Brasil e as operaçóes de paz em um mundo globalizado: entre a tradição e a inovaçáo. Brasília: Ipea, 2012, cap. 8, p. 213-242.

RAMIRES, C. A. Centro Conjunto de Operaçôes de Paz do Brasil: história e perspectivas pós-MINUSTAH (Capítulo 3). In: HAMANN, E.; TEIXEIRA, C. R. (Org.). A participaçáo do Brasil na MINUSTAH (2004-2017): percepções, lições e práticas relevantes para futuras missóes. Rio de Janeiro: CCOPAB, 2017, p. 25-35.

SILVA, F. M. Um balanço da Política Externa Brasileira sobre Assistência Humanitária Internacional. Revista de Estudos Internacionais, v. 2, n.1, p. 121-133, 2011. Disponível em: <http:// www.revistadeestudosinternacionais.com/uepb/index.php/ rei/article/download/48/pdf>. Acesso em: 20 fev. 2019.

SILVA, F. P. Da onda rosa à era progressista: a hora do balanço. Revista Sures, n. 5, p. 67-94, 2015. Disponível em: https:// revistas.unila.edu.br/sures/article/view/295. Acesso em $20 \mathrm{fev}$ 2019.

SOUZA NETO, D. M. Regional Defense Integration and Peacekeeping Cooperation in the Southern Cone. In: KENKEL, K. M. South America and Peace Operations - Coming of Age. Nova York: Routledge, 2013, chap. 3, p. 64-82.

SOUZA NETO, D. M.. Operaçóes de Paz e Cooperação Regional: O Brasil e o Envolvimento Sul-americano na MINUSTAH. Revista da Escola de Guerra Naval, Rio de Janeiro, n. 15, p. 25-58, 2010. Disponível em: https://revista.egn.mar.mil.br/index.php/revistadaegn/article/view/373. Acesso em: 20 fev 2019. TEIXEIRA JUNIOR, A. W. M.; SILVA, A. H. L. Explaining Defense Cooperation With Process-tracing: the Brazilian Proposal for the Creation of UNASUR South American Defense Council. Rev. bras. polít. int., Brasília, v. 60, n. 2, 2017. Dis- ponível em: <http://www.scielo.br/scielo.php?script=sci_arttext\&pid=S0034-73292017000200207 >. Acesso em: 20 fev. 2019.

UNASUL. Regulamento do Conselho de Defesa Sul-Americano. In: Normativa UNASUL-CDS-CEED-ESUDE, dez. 2008. Disponível em: <https://www.defesa.gov.br/arquivos/ relacoes_internacionais/unasul/normativa_unasul_2017.pdf >. Acesso em: 20 abr. 2019.

VAZ, A. C.; FUCCILLE, A.; REZENDE, L. P. UNASUR, Brazil, and the South American defence cooperation: A decade later. Rev. bras. polít. int., Brasília, v. 60, n. 2, ed. 12, 2017. Disponível em: <http://www.scielo.br/scielo.php?script=sci_ arttext\&pid=S0034-73292017000200211 >. Acesso em: 20 fev. 2019.

VITELLI, M. G. The South American Defense Council: the Building of a Community of Practice for Regional Defense. Rev. bras. polít. int., Brasília, v. 60, n. 2, 2017. Disponível em: <http://www.scielo.br/scielo.php?script=sci_arttext\&pid=S0034-73292017000200204>. Acesso em: 20 fev. 2019. 